\title{
MÉTODOS DE PREPARO DE SOLO E SUA INFLUÊNCIA NA EROSÃO HÍDRICA E NO ACÚMULO DE BIOMASSA DA PARTE AÉREA DE Eucalyptus saligna EM UM CAMBISSOLO HÁPLICO DA DEPRESSÃO CENTRAL DO RIO GRANDE DO SUL ${ }^{1}$
}

\author{
José Baptista² e Renato Levien ${ }^{3}$
}

\begin{abstract}
RESUMO - Este estudo buscou identificar e quantificar o efeito de métodos de preparo de solo e manejo de resíduos da colheita sobre a erosão hídrica e o desenvolvimento inicial da floresta de Eucalyptus saligna em um Cambissolo háplico. O ensaio foi instalado em área experimental da Aracruz Celulose e Papel S. A., localizada no Município de Arroio dos Ratos, na região fisiográfica denominada Depressão Central. O delineamento experimental utilizado foi o de blocos ao acaso com três repetições. Os tratamentos testados foram: subsolagem interrompida com resíduo (SIR), subsolagem contínua com resíduo (SCR) e subsolagem contínua sem resíduo (SSR), todos no sentido do declive, e coveamento mecânico (CME). A perda de solo do SSR foi 10 vezes maior que a dos demais tratamentos de subsolagem e 100 vezes maior em relação ao coveamento mecânico (CME). O escoamento superficial nos tratamentos com resíduo correspondeu a 1,6\% do total precipitado e no tratamento subsolagem sem resíduo, 2,9\% do total precipitado. O preparo mais intensivo do solo aumentou a erosão, porém favoreceu o crescimento inicial do eucalipto. A biomassa aérea do E. saligna 12 meses após o plantio foi maior nos tratamentos com maior volume de solo mobilizado.
\end{abstract}

Palavras-chave: Revolvimento de solo, Erosão hídrica e Eucalipto.

\section{METHODS OF SOIL TILLAGE AND ITS INFLUENCE IN WATER EROSION AND INITIAL DEVELOPMENT OF Eucalyptus Saligna ON THE INCEPTISOIL OF THE CENTRAL DEPRESSION OF THE STATE OF RIO GRANDE DO SUL}

\begin{abstract}
The study sought to identify and quantify the effect of methods of tillage soil and solid waste management of the harvest on water erosion and initial development of the forest in a Inceptisoil. The test was installed in an experimental area of Aracruz Pulp and Paper S. A., located in the municipality of Arroio dos Ratos in the physiografic region called the Depression Center. The experimental design used was random block with three repetitions. The treatments tested were interrupted ripping with residue (CRS), continuous ripping with residue (SCR), continuous without residue (SSR) all in the direction of the slope and mechanical digging (CME). The loss of soil from SSR was ten times larger than the other treatment of ripping and one hundred times greater if compared to mechanic digging. The water disposed superficial treatment with residue was $1.6 \%$. In ripping without residue, disposal was $2.9 \%$ of the total precipitate. The more intensive preparation increases soil erosion but favors the initial growth of eucalyptus. The maintenance of residue provides an appropriate development of eucalyptus plants and reduces the loss of water, and soil.
\end{abstract}

Keyword: Ripping of soil, Water erosion and Eucalyptus.

\footnotetext{
${ }^{1}$ Recebido em 17.01.2008 e aceito para publicação em 02.03.2010.

22ARACRUZ CELULOSE S.A., ARACRUZ, Brasil. E-mail: <jbaptista@cmpcrs.com.br>.

${ }^{3}$ Universidade Federal do Rio Grande do Sul, UFRGS, Brasil.
} 


\section{INTRODUÇÃO}

O preparo de solo para o plantio de espécies florestais objetiva disponibilizar quantidades suficientes de água e de nutrientes para o estabelecimento mais rápido das mudas. Em geral, as técnicas de preparo, além de visarem ao rápido crescimento do sistema radicular, por meio do revolvimento, o que facilita a absorção de água e de nutrientes, eliminam plantas indesejáveis próximas das mudas, evitando a competição (BARROS et al., 2003). O preparo de solo visa à sua degradação, diminuindo a resistência e facilitando o desenvolvimento do sistema radicular das árvores que passam a explorar maior volume de solo, aumentando sua absorção de água e nutrientes (FERNANDES e SOUZA, 2001). O preparo do solo pode acelerar a erosão hídrica, com valores de perdas acima da tolerância em determinado solo, reduzindo, assim, o seu potencial produtivo e a sustentabilidade em longo prazo (BERTONI et al., 1985; HERNANI et al., 1987; GONÇALVES et al., 2000).

As perdas de solo e água por erosão hídrica resultam da interação do clima, solo, topografia, cobertura e manejo do solo e adoção de práticas conservacionistas (WISCHMEIER e SMITH, 1978). Essas perdas podem ser reduzidas pela diminuição da capacidade de desagregação e transporte de sedimentos ocasionados pelos agentes erosivos (AMADO et al., 1989). No entanto, são fortemente influenciadas pelo preparo do solo (COGO, 1981; BERTOL, 1995), o qual influi nos atributos físicos da superfície e subsuperfície, entre as quais se destacam a estrutura, densidade e porosidade, que alteram a capacidade de infiltração de água e a suscetibilidade do solo à erosão (LARSON e GILL, 1973). Percebe-se, ainda, que o tipo de implemento utilizado e a intensidade do preparo influenciam na quantidade de resíduos culturais remanescentes na superfície do solo (SCHICK et al., 2000).

Em geral, há relação positiva entre o volume de solo preparado e o ritmo de crescimento das plantas. Poynton (1965) conduziu um experimento, em que demonstrou que o desenvolvimento de plantas de Eucalyptus saligna foi diretamente influenciado pela intensidade de preparo de solo até os seis anos após o plantio e que o maior crescimento das plantas ocorreu onde houve maior intensidade desse preparo.

Finger et al. (1996) constataram efeito positivo da subsolagem no crescimento do E. grandis até a idade de 3,5 anos em solo Podzólico com ocorrência de camada de impedimento, com 50\% de ganho no Diâmetro à Altura do Peito (DAP) e 35\% na altura relativamente ao solo não preparado. Stape et al. (2002), estudando o efeito de três sistemas de limpeza de terreno, preparo de solo e fertilização em dois sítios com solos e produtividades distintas na região de Entre Rios, BA, constataram efeito positivo do preparo de solo e da fertilização no crescimento inicial do eucalipto até os 12 meses de idade. O preparo com subsolagem apresentou os maiores valores para altura das árvores nos dois sítios, em comparação com o coveamento. No sítio com menor fertilidade do solo, a resposta à adubação e à queima dos resíduos foi maior do que no sítio mais fértil. Esses resultados demonstraram que o maior revolvimento do solo aumentou o crescimento inicial do eucalipto, por proporcionar melhores condições para o crescimento radicular, explorando volume maior do solo, o que proporcionou menor estresse das plantas na ocorrência de déficits hídricos.

Este estudo buscou identificar e quantificar o efeito de métodos de preparo de solo e manejo de resíduos da colheita sobre a erosão hídrica e o acúmulo de biomassa na parte aérea de plantas de E. saligna.

\section{MATERIAL E MÉTODOS}

O experimento foi instalado em outubro de 2006 em uma área de Cambissolo háplico pertencente à Aracruz Celulose e Papel S. A., no Horto Florestal Faxinal, localizado no Município de Arroio dos Ratos, na região fisiográfica denominada Depressão Central, nas coordenadas 30¹7‘59" S e 51³9‘43" W de Greenwich, a uma altitude de 125 macima donível do mar. O delineamento experimental utilizado foi o de blocos ao acaso com três repetições. O experimento foi acompanhado durante 12 meses até setembro de 2007. As avaliações do desenvolvimento inicial do eucalipto foram feitas aos 5 e 11 meses e as avaliações de perda de solo, realizadas durante todo o período. O clima da região, segundo a classificação de Köppen, é do tipo Cfa (subtropical úmido, com verão quente). A temperatura média anual é de $14,9^{\circ} \mathrm{C}$, sendo a média das mínimas de $14,8^{\circ} \mathrm{C}$ e a média das máximas, $24,3^{\circ} \mathrm{C}$. A precipitação pluvial média anual é de $1.325 \mathrm{~mm}$, apresentando, frequentemente, deficiência hídrica nos meses de novembro a março.

Para avaliar a precipitação mensal durante os 12 meses do estudo, utilizou-se um pluviômetro no local do ensaio. Na Figura 1 é possível visualizar a distribuição da precipitação mensal durante o período de estudo, comparativamente com a precipitação média histórica. 


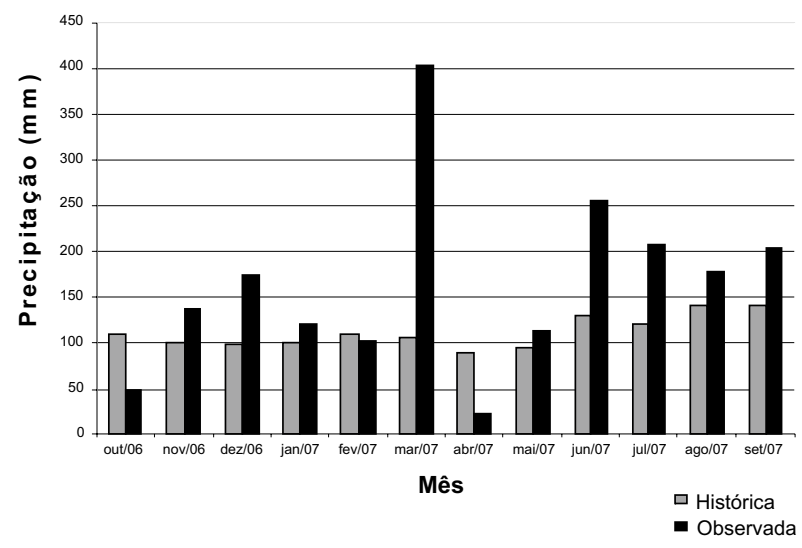

Figura 1 - Precipitação mensal na área experimental durante o período de avaliação e precipitação histórica.

Figure 1 - Monthly Precipitation in the experimental area during the evaluation period and historical precipitation.

O uso do solo no local do estudo antes da implantação do povoamento florestal era com pastagem. A primeira implantação data de junho de 1992, quando foi desenvolvida uma floresta de Eucalyptus grandis. O método de preparo de solo utilizado na época foi a subsolagem com três hastes na linha de plantio. A produtividade média de madeira com casca foi de $46 \mathrm{~m}^{3} \mathrm{ha}^{-1} \mathrm{ano}^{-1}$. A floresta foi colhida com 15 anos e possuía espaçamento médio de $3 \mathrm{~m}$ entre linhas e 2 m entre plantas da mesma linha. Na colheita foi utilizado o processador Harvester, para o corte e descascamento das árvores, e um Forwarder fez a retirada da madeira do interior do talhão. O tráfego das máquinas ocorreu entre as linhas de tocos, no sentido do declive. Os resíduos da colheita, que eram constituídos por folhas, galhos, pontas de árvores e cascas, foram mantidos no local e espalhados na área de maneira uniforme, ficando toda a superfície do solo coberta. O plantio atual foi realizado em 10 de outubro de 2006, com mudas clonais de Eucalyptus saligna.

O solo da área experimental foi classificado como Cambissolo háplico Tb distrófico léptico A proeminente textura média com cascalho/argilosa. Para a determinação dos atributos físicos do solo foram coletadas 16 amostras indeformadas em cilindros metálicos de volume conhecido, nas duas profundidades de $0-20 \mathrm{~cm}$ e $20-40 \mathrm{~cm}$. Foi retirada uma amostra por profundidade e por parcela. Imediatamente após a extração, as amostras foram envoltas em papel-alumínio. No Laboratório de
Física do Solo do Departamento de Solos da Faculdade de Agronomia da Universidade Federal do Rio Grande do Sul (UFRGS), as amostras foram cuidadosamente retiradas da lata e do papel-alumínio e saturadas em água, pesadas e logo em seguida colocadas em mesa de tensão a $60 \mathrm{~cm}$ de água durante $48 \mathrm{~h}$. Após esse período, cada amostra foi pesada, colocada em estufa a $105^{\circ} \mathrm{C}$ por $48 \mathrm{~h}$ e novamente pesada. Com esse procedimento foram determinados: densidade do solo, macro e microporosidade e volume total de poros, segundo EMBRAPA(1997).

Para a caracterização química do solo foram retiradas 16 amostras compostas nas profundidades de $0-20 \mathrm{~cm}$ e $20-40 \mathrm{~cm}$. As amostras coletadas foram enviadas para o Laboratório de Análises de Solos do Departamento de Solos da Faculdade deAgronomia da UFRGS. As análises químicas do solo foram realizadas utilizando-se a metodologia descrita por Tedesco (1995).

Os tratamentos escolhidos para o experimento foram baseados em práticas de manejo que são, por vezes, empregados no estabelecimento de povoamentos florestais. Por esse motivo foi montado um experimento visando analisar os efeitos dos diferentes tipos de preparos do solo para o cultivo de eucalipto no crescimento inicial das mudas e nas perdas por erosão de sedimentos, água e nutrientes. Foram utilizados quatro métodos de preparo de solo: Subsolagem Interrompida com Resíduo (SIR), Subsolagem Contínua com Resíduo (SCR), Subsolagem Contínua sem Resíduo (SSR) e Coveamento Mecânico (CME).

O delineamento experimental utilizado foi o de blocos ao acaso com três repetições. Os blocos foram demarcados aleatoriamente dentro do horto florestal. As dimensões das parcelas experimentais montadas foram de $6 \mathrm{~m}$ x $22 \mathrm{~m}$ e compostas por duas linhas, possuindo cada uma oito mudas no espaçamento de 3,0 m x 3,0 m. Nas parcelas foram utilizadas bordaduras de oito mudas e uma linha no sentido do declive. A área total de área que cada bloco possui é de $858 \mathrm{~m}^{2}$.

Para a confecção das covas foi utilizada uma broca com 45 cm de diâmetro acoplada em um trator Massey Ferguson 275 com 75 CV. A profundidade de trabalho da broca foi de $60 \mathrm{~cm}$. Para tracionar o subsolador de três hastes, foi utilizado trator de esteira Komatsu D50 com 90 CV. A haste principal do subsolador possuía um comprimento de $65 \mathrm{~cm}$, e a largura da ponteira era de $7 \mathrm{~cm}$. As hastes secundárias possuíam $50 \mathrm{~cm}$ de

Revista Árvore, Viçosa-MG, v.34, n.4, p.567-575, 2010 
profundidade com ponteiras de mesma dimensão da haste principal. As hastes secundárias têm como função fechar o sulco aberto pela haste principal, por isso foram dispostas $50 \mathrm{~cm}$ atrás dela. Na parcela de preparo interrompido foi utilizado o mesmo subsolador, porém o implemento foi levantado de $3 \mathrm{~m}$ em $3 \mathrm{~m}$, aproximadamente, para dar descontinuidade ao preparo. Nas parcelas do tratamento SSR, o resíduo foi arrastado com o auxílio do subsolador, que varreu a maior parte para fora da parcela, e as sobras foram retiradas manualmente no momento da instalação das parcelas. Todos os preparos foram realizados no sentido do declive em função da disposição dos tocos do cultivo anterior.

Para correção da acidez do solo, antes do preparo foi aplicado a lanço 1,5 $\mathrm{Mg}_{\text {ha }}{ }^{-1}$ de calcário dolomítico, cujo PRNT foi de $65 \%$. Junto com o preparo de solo foram aplicados $400 \mathrm{~kg} \mathrm{ha}^{-1}$ de fosfato natural reativo com $31,2 \%$ de $\mathrm{P}_{2} \mathrm{O}_{5}$ total. Nas parcelas com covas (CME), o fosfato foi colocado manualmente em doses de $360 \mathrm{~g}$ por cova. Após o plantio foi realizada a adubação de arranque em covetas laterais, utilizando-se $110 \mathrm{~g}$ de adubo NPK 6-30-6 por planta. Aos quatro meses após o plantio foram aplicados $150 \mathrm{~g}$ de adubo NPK 15-5-30 por muda, distribuídos na projeção da copa.

A área experimental foi mantida sempre livre de matocompetição, através do controle das ervas infestantes e eliminação das cepas utilizando herbicida à base de glifosato.

O resíduo florestal sobre o solo na época dos tratamentos era composto por galhos com diâmetro de até $15 \mathrm{~cm}$, casca e folhas oriundas da colheita mecanizada de árvores e que permaneciam no interior do talhão espalhado de maneira uniforme. Para quantificar os resíduos deixados pela colheita foi utilizado um quadro de madeira de $0,49 \mathrm{~m}^{2}$. Realizaram-se quatro lançamentos de forma aleatória, e coletaram-se todos os resíduos encontrados no interior da área do amostrador. Os resíduos tiveram a sua umidade determinada, para obtenção do peso de matéria seca por hectare.

Para avaliar os efeitos dos diferentes métodos de preparo de solo na sua imobilização, foi mensurado o volume de solo mobilizado (VSM), determinado conforme a metodologia descrita por Sasaki (2005). O volume de solo mobilizado por hectare para o preparo de solo com subsolagem foi baseado no espaçamento entre linhas de plantio, de acordo com a equação proposta por Wichert (2005):
$\mathrm{VSM}=\mathrm{ASM} \cdot \underline{10000}$

$\mathrm{L}$

em que VSM = volume de solo mobilizado $\left(\mathrm{m}^{3} \mathrm{ha}^{-1}\right)$, ASM = área de solo mobilizado $\left(\mathrm{m}^{2}\right)$ e $\mathrm{L}=$ espaçamento entre linhas de plantio.

Para determinar a área de solo mobilizado foram realizadas sondagens transversais a cada $10 \mathrm{~cm}$ e com o auxílio de uma haste graduada foram mensuradas as profundidades de preparo em cada ponto. Para o cálculo da área mobilizada, foi determinada a superfície de cada figura geométrica formada pela profundidade preparada, bem como a distância entre pontos. Considerou-se área preparada aquela que não encontrou resistência à penetração da haste graduada.

Foram feitas sondagens transversais a cada $5 \mathrm{~m}$ ao longo das linhas de preparo de todas as parcelas. O rompimento lateral observado foi de $50 \mathrm{~cm}$ para ambos os lados. O VSM para o tratamento coveamento mecânico foi calculado pela fórmula:

$$
\mathrm{VSM}=\pi \mathrm{R}^{2} . \mathrm{G} \cdot \underline{10000}
$$

$$
\text { L } x \text { E }
$$

em que VSM = volume de solo mobilizado $\left(\mathrm{m}^{3} \mathrm{ha}^{-1}\right)$, ASM = área de solo mobilizado $\left(\mathrm{m}^{2}\right), \mathrm{G}=$ profundidade da cova, $L$ = espaçamento entre linhas de plantio e $\mathrm{E}=$ espaçamento entre plantas.

As parcelas tiveram as dimensões de $6 \mathrm{~m}$ x $25 \mathrm{~m}$, sendo a maior dimensão da parcela direcionada no sentido do declive. As parcelas foram cercadas com chapas galvanizadas de $40 \mathrm{~cm}$ de largura, enterradas a uma profundidade de $20 \mathrm{~cm}$. Na extremidade inferior da parcela foi colocada uma calha coletora para conduzir a enxurrada até os tanques coletores. O sistema coletor foi constituído de um tanque de sedimentação, com capacidade para $250 \mathrm{~L}$, munido de um sistema divisor tipo Geib de 15 janelas e um tanque coletor de água e sedimentos com capacidade para $500 \mathrm{~L}$. A partir do sistema divisor, através de uma canaleta, a água e sedimentos foram conduzidos para o tanque coletor. Assim, após o enchimento do tanque de sedimentação, 1/15 de água da enxurrada foi conduzida para o segundo tanque. Dentro do tanque de sedimentação foi colocado um recipiente para coleta de sedimentos. As coletas foram realizadas a cada evento de chuva, quando era registrado o volume das precipitações, peso da água e peso do sedimento. Antes da coleta, a água era agitada, 
e somente então se retirava a amostra para sedimentação. As amostras foram enviadas ao Laboratório de Física do Solo da UFRGS para a quantificação de solo suspenso na solução coletada. Para precipitar o sedimento das amostras foram acrescentados $10 \mathrm{~mL}$ de solução contendo alúmen de potássio. Os sedimentos foram secos em estufa a $60{ }^{\circ} \mathrm{C}$ por $72 \mathrm{~h}$ e posteriormente pesados. Os sedimentos depositados nos recipientes dentro do tanque foram retirados e enviados para secar em estufa para posterior pesagem e cálculo de peso de matéria seca de solo e água das amostras.

A água armazenada nos tanques foi retirada com o auxílio de um balde e posteriormente pesada. A altura da coluna de água foi medida com trena. As coletas de água foram realizadas entre outubro de 2006 e setembro de 2007. Após as coletas e medições, os tanques eram esvaziados e limpos e os valores de perda de solo e água, anotados.

A biomassa da parte aérea foi obtida pela soma das biomassas dos galhos, folhas, casca e lenho. Essas biomassas foram obtidas através de derrubada de 12 árvores no sétimo mês e 12 árvores no décimo primeiro mês após o plantio. As árvores derrubadas tinham a altura igual à altura média de cada parcela útil amostrada.

\section{RESULTADOS E DISCUSSÕES}

Segundo as análises, há a necessidade de elevar os teores de NPK, pois são baixos ou limitantes para o adequado desenvolvimento do povoamento florestal. Os valores dos atributos físicos, teores de argila, matéria orgânica e declividade medidos antes do preparo do solo encontram-se na Tabela 1.
Os menores valores da macroporosidade encontram-se na camada de 0 a $20 \mathrm{~cm}$ de profundidade, com exceção do bloco 3, que apresentou valores de macroporosidade na camada mais profunda do perfil.

Os valores observados estão acima das condições ideais de macroporosidade determinada por Da Ros et al. (1997), que observaram que as condições ideais estão na faixa de 0,09 a $0,12 \mathrm{~m}^{3} \cdot \mathrm{m}^{-3}$, podendo a redução da macroporosidade causar decréscimo da permeabilidade do solo.

A quantidade de resíduo gerado nas áreas de reforma dos povoamentos florestais é influenciada pela idade de corte da floresta e pelo sistema de colheita. Povoamentos mais antigos, em geral, geram quantidades maiores de resíduos. Colheitas realizadas para produção de produtos sólidos de madeira geram mais resíduos se comparadas com sistemas cujo objetivo final é a celulose ou madeira para energia.

Os valores encontrados da biomassa dos resíduos variaram de 28,8 $\mathrm{Mg} \mathrm{ha}^{-1}$ a 43,6 $\mathrm{Mg} \mathrm{ha}^{-1}$, sendo o valor médio calculado de 35,9 $\mathrm{Mg} \mathrm{ha}^{-1}$ de resíduos deixados pela colheita mecanizada no sistema "HarvesterForwarder”. A biomassa dos resíduos foi constituída de ponta de galhos, folhas e cascas espalhadas uniformemente na área.

A área da secção mobilizada de solo com o coveador mecânico apresentou contraste, se comparado com as subsolagens. O menor revolvimento de solo torna o coveamento mecânico uma alternativa para relevos acidentados pelo seu baixo volume de solo mobilizado (Tabela 2).

Tabela 1 - Teores de argila, declividade média e atributos físicos do horizonte superficial do solo nas profundidades de 0-20 e 20-40 cm, nas três repetições da área experimental.

Table 1 - Contents of clay, slope and average physical attributes of the surface soil horizon at depths of 0-20 and $20-40 \mathrm{~cm}$ in three replicates of the experimental area.

\begin{tabular}{|c|c|c|c|c|c|c|c|c|}
\hline \multirow[t]{2}{*}{ Bloco } & \multirow[t]{2}{*}{ Prof. ${ }^{1}$} & \multirow[t]{2}{*}{ M.O. $^{2}$} & \multirow[t]{2}{*}{ Argila } & \multicolumn{3}{|c|}{ Porosidade } & \multirow[t]{2}{*}{ Den. $^{3}$} & \multirow[t]{2}{*}{ Dec. $^{4}$} \\
\hline & & & & Micro & Macro & Total & & \\
\hline $\mathrm{N}^{\circ}$ & $\mathrm{cm}$ & 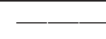 & - & 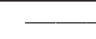 & $-\mathrm{m}^{3} \mathrm{~m}^{-3}$ & & $\mathrm{~g} \mathrm{~cm}^{-3}$ & $\%$ \\
\hline \multirow[t]{2}{*}{1} & $0-20$ & 2.2 & 20 & 0,22 & 0,16 & 0,38 & 1,56 & 21,5 \\
\hline & $20-40$ & 1.7 & 18 & 0,18 & 0,22 & 0,40 & 1,56 & 21,5 \\
\hline \multirow[t]{2}{*}{2} & $0-20$ & 2.2 & 22 & 0,20 & 0,25 & 0,45 & 1,60 & 12,3 \\
\hline & $20-40$ & 2.2 & 25 & 0,21 & 0,16 & 0,37 & 1,70 & 12,3 \\
\hline \multirow[t]{2}{*}{3} & $0-20$ & 2.4 & 19 & 0,14 & 0,24 & 0,38 & 1,68 & 16,5 \\
\hline & $20-40$ & 2.0 & 20 & 0,16 & 0,22 & 0,38 & 1,69 & 16,5 \\
\hline
\end{tabular}

1 - Profundidade; 2 - Matéria orgânica; 3 - Densidade do solo; e 4 - Declividade.

1 - Depth; 2 - Organic material; 3 - Soil Density; and 4 -Slope.

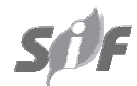

Revista Árvore, Viçosa-MG, v.34, n.4, p.567-575, 2010 
Tabela 2 - Área da secção transversal de solo mobilizado (ASM) e volume de solo mobilizado (VSM) nos tratamentos de preparo de solo.

Table 2 - Area of the cross-section of soil mobilised (ASM) and volume of soil mobilised (VSM) in the treatment of soil preparation.

\begin{tabular}{llcccc}
\hline Sigla & Preparo de solo & ASM & & VSM \\
\hline & & $\mathrm{m}^{2}$ & & $\mathrm{~m}^{3} \mathrm{ha}^{-1}$ \\
SSR & Subsolagem contínua sem resíduo & 0,41 & $\mathrm{a}$ & 1380,0 & $\mathrm{a}$ \\
SCR & Subsolagem contínua com resíduo & 0,32 & $\mathrm{~b}$ & 1080,0 & $\mathrm{~b}$ \\
SIR & Subsolagem interrompida com resíduo & 0,29 & $\mathrm{c}$ & 1018,3 & $\mathrm{c}$ \\
CME & Coveamento mecânico & 0,16 & $\mathrm{~d}$ & 77,3 & $\mathrm{~d}$ \\
\hline
\end{tabular}

Médias seguidas de mesma letra minúscula nas colunas e maiúscula na linha não diferem entre si, pelo teste de Duncan (P<0,05). Averages followed by the same lower case letter in the columns and upper case letters in the lines do not differ, by the Duncan test $(P<0.05)$.

A grande quantidade de resíduo obrigou o trator a levantar continuamente a haste subsoladora. Por essa razão, os valores de área de solo mobilizado dos tratamentos SCR e SIR foram estatisticamente diferentes. A subsolagem contínua sem resíduo mostrou-se uma das formas mais intensas de preparo do solo, pois a retirada do resíduo facilitou o preparo, dando melhor condição de trafegabilidade para o trator e evitou o embuchamento de cascas e galhos nas hastes. Portanto, o efeito do resíduo no preparo de solo diminuiu a área preparada de $0,41 \mathrm{~m}^{2}$ para $0,32 \mathrm{~m}^{2}$.

As perdas anuais de solo observadas variaram de 0,16 $\mathrm{Mg} \mathrm{ha}^{-1}$ na área coveada (CME) até $11,05 \mathrm{Mg}$ $\mathrm{ha}^{-1}$ no preparo realizado na parcela sem resíduo (SSR), conforme a Tabela 3 .
A subsolagem sem resíduo (SSR) apresentou perdas de solo acima da tolerância estimada como aceitável por Lombardi Neto e Bertoni (1975), com modificações de Bertol e Almeida (2000), em que os valores de perdas de solo para Cambissolo variam de 6,3 a 7,2 $\mathrm{Mg} \mathrm{ha}^{-1} \mathrm{ano}^{-1}$. A prática de preparo mais conservacionista foi o coveamento mecanizado (CME), cuja perda de solo foi de $0,16 \mathrm{Mg} \mathrm{ha}^{-1} \mathrm{ano}^{-1}$. As perdas de solo dos tratamentos com subsolagem onde não houve a retirada do resíduo apresentaram valores bem próximos. A subsolagem interrompida com resíduo (SIR) apresentou perdas de solo por erosão de 1,39 $\mathrm{Mg} \mathrm{ha}^{-1} \mathrm{ano}^{-1} \mathrm{e}$ na subsolagem contínua com resíduo (SCR) de 1,57 $\mathrm{Mg} \mathrm{ha}^{-1} \mathrm{ano}^{-1}$. As perdas de solo quantificadas nos tanques coletores dos tratamentos SIR e SCR foram baixas, porém foi verificada a ocorrência de

Tabela 3 - Perdas de solo durante o período de avaliação e precipitação medida.

Table 3 - Loss of soil during the assessment period and precipitation measure.

\begin{tabular}{lccccc}
\hline Meses & \multicolumn{2}{c}{ Perdas de solo observadas $\left(\mathrm{Mg} \mathrm{ha}^{-1}\right)$} & \multicolumn{2}{c}{$\begin{array}{c}\text { Precipitação } \\
\text { total }\end{array}$} \\
\hline & SIR & SSR & SCR & CME & $(\mathrm{mm})$ \\
\hline Outubro & 0,00 & 0,01 & 0,00 & 0,00 & 49 \\
Novembro & 0,12 & 0,50 & 0,30 & 0,00 & 138 \\
Dezembro & 0,10 & 0,90 & 0,01 & 0,00 & 154 \\
Janeiro & 0,20 & 0,14 & 0,20 & 0,00 & 132 \\
Fevereiro & 0,20 & 0,80 & 0,2 & 0,01 & 154 \\
Março & 0,31 & 4,45 & 0,49 & 0,04 & 403 \\
Abril & 0,00 & 0,00 & 0,00 & 0,00 & 22 \\
Maio & 0,09 & 0,4 & 0,10 & 0,00 & 113 \\
Junho & 0,04 & 1,38 & 0,08 & 0,00 & 255 \\
Julho & 0,16 & 0,16 & 0,12 & 0,01 & 208 \\
Agosto & 0,10 & 0,39 & 0,01 & 0,00 & 177 \\
Setembro & 0,07 & 11,05 & 1,06 & 0,16 & 204 \\
\hline Total & 1,39 & & & 2.010 \\
\hline
\end{tabular}

Revista Árvore, Viçosa-MG, v.34, n.4, p.567-575, 2010 
processos erosivos no interior das parcelas. Os sedimentos foram se acumulando onde o preparo foi interrompido pelo acúmulo de resíduo.

Nesse caso, pode-se observar a importância da manutenção dos resíduos no interior do talhão, pois o tratamento SSR apresentou perdas de solos que extrapolaram os limites de tolerância. As perdas de solo mais significativas ocorreram com precipitações mensais maiores que $200 \mathrm{~mm}$. Os valores do escoamento superficial foram semelhantes onde o resíduo permaneceu no campo (Tabela 4). A perda de água por enxurrada foi maior na parcela onde o resíduo foi retirado (SSR), sendo as maiores perdas registradas entre os meses de junho e setembro. A perda de água no tratamento subsolagem sem resíduo (SSR) foi 11 vezes maior do que a registrada no tratamento subsolagem com resíduo (SCR) no mês de junho. De acordo com Cogo et al. (2003), a cobertura do solo proporcionada por resíduos culturais deixados na superfície do solo tem ação direta e efetiva na redução da erosão hídrica. Isso se relaciona com a dissipação de energia cinética das gotas de chuva que diminui a desagregação das partículas do solo e o selamento superficial e aumenta a infiltração de água.

Na Figura 2, observa-se que nos dois primeiros meses o escoamento superficial acumulado foi similar nos quatros tratamentos, porém a partir do quarto mês de avaliação a perda de água no tratamento SSR foi de $40 \%$, se comparado com os tratamentos SCR e SIR.

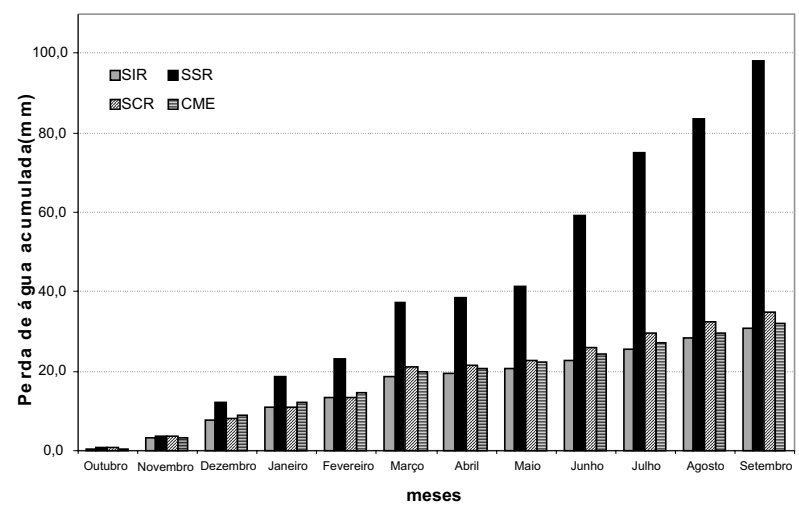

Figura 2 - Perda de água acumulada por escoamento superficial durante o período de avaliação.

Figure 2 - Loss of water accumulated by runoff during the assessment period.

No final da avaliação, os valores de perda de água acumulada na parcela sem resíduo foi três vezes maior que os dos tratamentos com resíduos.

Como demonstrado na Tabela 6, a biomassa total das mudas de eucalipto plantadas nas parcelas sem resíduo (SSR) foi $80 \%$ maior, se comparada ao tratamento CME. Essa diferença pode ser explicada pelo fato de que as parcelas do preparo sem resíduo (SSR) proporcionaram maior volume de solo mobilizado, criando condições físicas favoráveis ao adequado desenvolvimento das raízes e, consequentemente, um aporte maior de biomassa

Tabela 4 - Perda de água por escoamento superficial durante o período de avaliação e precipitação medida. Table 4 - Loss of water by runoff during the assessment period and precipitation measure.

\begin{tabular}{|c|c|c|c|c|c|c|c|c|c|}
\hline \multirow[t]{3}{*}{ Meses } & \multicolumn{8}{|c|}{ Perda da água por escoamento superficial } & \multirow{3}{*}{$\begin{array}{c}\mathrm{Ppt} * \\
\text { total }\end{array}$} \\
\hline & \multicolumn{2}{|c|}{ SIR } & \multicolumn{2}{|c|}{ SSR } & \multicolumn{2}{|c|}{ SCR } & \multicolumn{2}{|c|}{ CME } & \\
\hline & $(\mathrm{mm})$ & $(\%)$ & $(\mathrm{mm})$ & $(\%)$ & $(\mathrm{mm})$ & $(\%)$ & $(\mathrm{mm})$ & $(\%)$ & \\
\hline Outubro & 0,7 & 1,0 & 0,9 & 1,3 & 0,8 & 1,1 & 0,7 & 1,0 & 49 \\
\hline Novembro & 2,5 & 1,7 & 3,1 & 2,0 & 2,8 & 1,8 & 2,6 & 1,7 & 138 \\
\hline Dezembro & 4,8 & 2,6 & 8,4 & 4,8 & 4,5 & 2,6 & 5,7 & 3,0 & 154 \\
\hline Janeiro & 3,0 & 2,1 & 6,3 & 4,2 & 2,8 & 2,0 & 3,3 & 2,3 & 132 \\
\hline Fevereiro & 2,3 & 1,5 & 4,5 & 2,8 & 2,4 & 1,5 & 2,4 & 1,6 & 154 \\
\hline Março & 5,5 & 1,4 & 14,1 & 3,5 & 7,8 & 1,9 & 5,3 & 1,3 & 403 \\
\hline Abril & 0,6 & 2,8 & 1,2 & 5,6 & 0,5 & 2,1 & 0,6 & 2,7 & 22 \\
\hline Maio & 1,6 & 1,4 & 2,8 & 2,5 & 1,4 & 1,2 & 1,4 & 1,3 & 113 \\
\hline Junho & 1,6 & 0,6 & 17,8 & 7,0 & 3,0 & 1,2 & 2,3 & 0,9 & 255 \\
\hline Julho & 3,0 & 1,3 & 15,8 & 7,0 & 3,7 & 1,8 & 3,0 & 1,3 & 208 \\
\hline Agosto & 3,0 & 1,7 & 8,4 & 4,7 & 2,8 & 1,5 & 2,1 & 1,2 & 177 \\
\hline Setembro & 2,3 & 1,3 & 14,7 & 8,2 & 2,7 & 1,5 & 2,5 & 1,4 & 204 \\
\hline Total & 30,8 & 1,5 & 98,1 & 4,6 & 35,1 & 1,7 & 32,0 & 1,6 & 2010 \\
\hline
\end{tabular}

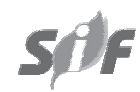

Revista Árvore, Viçosa-MG, v.34, n.4, p.567-575, 2010 
Tabela 5 - Biomassa de Eucalyptus saligna por tratamento durante o período de estudo. Table 5 - Biomass of Eucalyptus saligna by treatment during the study period.

\begin{tabular}{|c|c|c|c|c|c|c|}
\hline \multirow[t]{3}{*}{ Tratamento } & \multirow[t]{3}{*}{ Idade (meses) } & \multicolumn{5}{|c|}{ Biomassa } \\
\hline & & Folha & Galho & Casca & Lenho & \multirow[t]{2}{*}{ Total } \\
\hline & & & & - Mg/ha - & & \\
\hline SSR & 7 & 4,46 a & $2,80 \mathrm{a}$ & 0,48 a & 2,44 a & $\overline{10,19 a}$ \\
\hline SIR & & $2,28 \mathrm{c}$ & $1,88 \mathrm{~b}$ & $0,34 \mathrm{~b}$ & $1,53 \mathrm{~b}$ & $6,04 \mathrm{~b}$ \\
\hline SCR & & $2,88 \mathrm{~b}$ & $1,58 \mathrm{c}$ & $0,35 \mathrm{~b}$ & $1,61 \mathrm{c}$ & $6,41 \mathrm{~b}$ \\
\hline CME & & $1,10 \mathrm{~d}$ & $0,45 \mathrm{~d}$ & 0,13 с & $0,37 \mathrm{~d}$ & $2,02 \mathrm{c}$ \\
\hline SSR & 11 & 4,55 a & 2,99 a & 0,66 a & 3,00 a & 11,23 a \\
\hline SIR & & $3,27 \mathrm{~b}$ & $1,78 \mathrm{c}$ & $0,56 \mathrm{~b}$ & $2,25 \mathrm{~b}$ & 7,86 с \\
\hline SCR & & $3,24 \mathrm{~b}$ & $2,27 \mathrm{~b}$ & 0,53 bc & $2,23 \mathrm{~b}$ & $8,27 \mathrm{~b}$ \\
\hline CME & & $1,11 \mathrm{c}$ & $0,49 \mathrm{~d}$ & $0,45 \quad \mathrm{C}$ & $0,51 \mathrm{c}$ & $2,56 \mathrm{~d}$ \\
\hline
\end{tabular}

Os valores seguidos de mesma letra nas colunas não diferem entre si, pelo teste de Duncan (P<0,05).

aérea. Foi significativa também a diferença entre os valores de biomassa do tratamento SSR com os demais tratamentos. O tratamento SSR apresentou menor incremento de biomassa (9\%) entre as medições realizadas no sétimo e décimo primeiro mês, tendo os tratamentos SCR, SIR e CME apresentado incrementos de 22,8\%, 22,5\% e 21,0\%, respectivamente. A Tabela 6 mostra que houve diferença significativa entre os compartimentos casca, folha e lenho dos tratamentos SIR e SCR. No entanto, essa diferença deixa de existir a partir do décimo primeiro mês após o plantio do eucalipto.

\section{CONCLUSÃO}

A subsolagem sem resíduo a favor do declive mostrou-se o método de preparo mais erosivo e o coveamento manual com resíduo, o que resultou em menor perda de solo, com perda anual de 11,05 Mg $\mathrm{ha}^{-1} \mathrm{ano}^{-1}$ e $0,16 \mathrm{Mg} \mathrm{ha}^{-1} \mathrm{ano}^{-1}$, respectivamente.

Os totais de água perdida por escoamento superficial nos tratamentos subsolagem interrompida com resíduo (SIR), subsolagem contínua com resíduo (SCR) e coveamento mecanizado (CME) foram semelhantes e da ordem de $20 \%$ da água precipitada no período analisado. Na subsolagem sem resíduo, o escoamento foi de $53,5 \%$.

A biomassa aérea do E. saligna aumentou com o volume de solo mobilizado, sendo ela aproximadamente cinco vezes maior no tratamento subsolagem contínua sem resíduo do que no coveamento mecânico aos 11 meses depois do plantio.

Revista Árvore, Viçosa-MG, v.34, n.4, p.567-575, 2010

\section{REFERÊNCIAS}

AMADO, T. J. C.; COGO, N. P.; LEVIEN, R. Eficácia relativa do manejo de resíduo cultural de soja na redução das perdas de solo por erosão hídrica. Revista Brasileira de Ciência do Solo, v.13, n.1, p.151-157, 1989.

BARROS, N. F.; NEVES, J. C. L. Efeito do método de preparo do solo, em área de reforma, nas suas características, na composição mineral e na produtividade de plantações de Eucalyptus grandis. Revista Árvore, v.27, n.5, p.635-646, 2003.

BERTOL, I. \& ALMEIDA, J. A. Tolerância de perda de solo por erosão para os principais solos do estado de Santa Catarina. Revista

Brasileira de Ciência do Solo, v.24, NUMERO, p.657-668, 2000.

BERTOL, I. Comprimento crítico de declive para preparos conservacionistas de solo., 1995. 185f. Tese (Doutorado) Universidade Federal do Rio Grande do Sul, Porto Alegre, 1995.

BERTONI, J. F.; LOMBARDI NETO, F. Conservação do solo. Piracicaba: Livro Ceres, 1985. 392p.

COGO, N. P. Effect of residue cover, tillage induced-roughness, and slope lenght on erosion and related parameters. 1981. 346f. Tese (Doutorado) Purdue University, West Lafayette, 1981. 
COGO, N. P.; LEVIEN, R.; SCHWARZ, R. A. Perdas de solo e água por erosão hídrica influenciadas por métodos de preparo, classes de declive e níveis de fertilidade do solo. Revista Brasileira de Ciência do Solo, v.27, p.743-753, 2003.

DA ROS, C. O. et al. Manejo do solo a partir de campo nativo: efeito sobre a forma e estabilidade da estrutura ao final de cinco anos. Revista Brasileira de Ciência do Solo, v.21, n.2, p.241-247, 1997.

FERNANDES, H. C.; SOUZA, A. P. Compactação de solos florestais: Uma questão para estudos. Revista Árvore, v.25, n.3, p.387-392, 2001.

FINGER, C. A. G. et al. Influência da camada de impedimento no solo sobre o crescimento de Eucalyptus grandis (Hill) ex Maiden. Ciência Florestal, v.6, n.1, p.137-145, 1996.

GONÇALVES, J. L. M. et al. Reflexos do cultivo mínimo e intensivo do solo em sua fertilidade e na nutrição das árvores. In: GONÇALVES, J. L. M.; BENEDETTI, V. (Eds.) Nutrição e fertilização florestal. Piracicaba: IPEF, 2000. p.1-57.

HERNANI, L. C. et al. Influência de métodos de limpeza do terreno sob floresta secundária em Latossolo amarelo do Vale do Ribeiro, SP: II. Perdas por erosão. Revista Brasileira de Ciência do Solo, v.11, n.2, p.215-219, 1987.

LARSON, W. E. \& GILL, W. R. Soil physical parameters for designing new tillage systems. In: NATIONAL CONSERVATION TILLAGE CONFERENCE, 1973, Ankeny. Proceedings.. Ankeny: Soil Consevation Society of America, 1973. p.13-22.
LOMBARDI NETO, F.; BERTONI, J. Erodibilidade de solos paulistas. Campinas: Instituto Agronômico de Campinas, 1975. 12p. (Boletim Técnico, 27).

POYTON, R. J. Research the silviculture of eucalyptus grandis (saligna) in the northern transvaal. South African Forestry Journal, v.55, n.1, p.10-20, 1965.

SASAKI, C. M. Desempenho operacional de um subsolador em função da estrutura, do teor de argila e de água de três latossolos. 2005. 82f. Tese (Doutorado em Recursos Florestais) - Escola Superior de Agricultura “Luiz de Queiroz”, Universidade de São Paulo, Piracicaba, 2005.

SCHICK, J. et al. Erosão hídrica em Cambissolo Húmico alumínico submetido a diferentes sistemas de preparo e cultivo do solo. Revista Brasileira de Ciência do Solo, v.24, p.427-436, 2000.

STAPE, J. L. et al. Definições de métodos de preparo de solo para silvicultura em solos coesos do litoral norte da Bahia. In: GONÇALVES, J. L. M.; STAPE, J. L. (Eds.). Conservação e cultivo de solos para plantações florestais. Piracicaba: IPEF, 2002. p.259-296.

TEDESCO, M. J. et al. Análise de solo, plantas e outros materiais. 2.ed. Porto Alegre: Universidade Federal do Rio Grande do Sul, 1995. 174p.

WISCHMEIER, W. H.; SMITH, D. D. Predicting rainfall erosion losses: a guide to conservation planning. Washington: USDA, 1978. 58p. (Agricultural Handbook, 537). 
